\title{
Leisure-time physical activity and its correlates in a multi-ethnic sample of adults over age 50 in Singapore
}

\author{
Joelle H. Fong®
}

\begin{abstract}
Background: To examine the prevalence and correlates of regular leisure-time physical activity (LTPA) among community-dwelling adults in Singapore.

Methods: Data was sourced from the 2018-2019 Singapore Life Panel, which asked respondents about their current LTPA participation at various time-points over a seven-month period. The final sample comprised 7684 subjects over age 50 . We applied logistic regression models in our analysis.

Results: $39.8 \%$ of the respondents engaged in regular LTPA, with significantly higher proportions of men than women doing so. Factors positively associated with regular LTPA in both genders were age, education, retired, income, and satisfaction with social life, whereas a negative association was found with self-rated health. The correlates of sustained LTPA participation were relatively consistent with factors predicting current participation.

Conclusions: Regular participation in recreational physical activities is important to promoting health and wellbeing among middle-aged and older adults as populations age. Our findings indicated that positive perceptions of social relationships and being retired are important supporting factors. The urgent development of physical activity promotion strategies and interventions are required to foster greater overall LTPA participation.
\end{abstract}

Keywords: Physical activity, Exercise, Population aging, Retirement

\section{Background}

Leisure-time physical activity (LTPA) has been defined as "physical activity performed during exercise, recreation or any time other than those associated with one's regular occupation, housework, or transportation", and is often distinguished from other domains of physical activity (e.g. occupational physical activity) in public health research [1]. Regular LTPA is defined as engaging in moderate or vigorous physical activity during leisure time for at least several times a week [2-4]. The surveillance of LTPA, including regular LTPA, among mid-age and older adults is particularly important since exercise

Correspondence: j.fong@nus.edu.sg

National University of Singapore, Postal: 469C Bukit Timah Road, Singapore 259771, Singapore

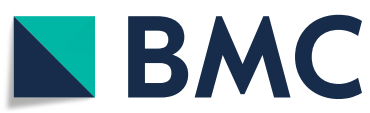

can attenuate physiological declines associated with aging and disuse, and is associated with improved functional and mental health, lower risk of chronic diseases, subjective well-being, and better quality of life [5-11].

A substantial proportion of adults, however, do not participate in LTPA. This is especially so in some aging Asian societies [12-15]. An early study conducted in 1998 reports that $57.9 \%$ of persons aged $60+$ in Singapore did not participate in regular LTPA [12]. More recent evidence indicates that, in around 20072008, the proportion of older adults reporting no LTPA/ exercise is $62.7 \%$ in Taiwan (PRC) and $67.7 \%$ in Shanghai, China $[13,14]$. This contrasts with the lower levels of LTPA non-participation among mid-age and older persons that have been observed in the United States

(c) The Author(s). 2021 Open Access This article is licensed under a Creative Commons Attribution 4.0 International License, which permits use, sharing, adaptation, distribution and reproduction in any medium or format, as long as you give appropriate credit to the original author(s) and the source, provide a link to the Creative Commons licence, and indicate if changes were made. The images or other third party material in this article are included in the article's Creative Commons licence, unless indicated otherwise in a credit line to the material. If material is not included in the article's Creative Commons licence and your intended use is not permitted by statutory regulation or exceeds the permitted use, you will need to obtain permission directly from the copyright holder. To view a copy of this licence, visit http://creativecommons.org/licenses/by/4.0/ The Creative Commons Public Domain Dedication waiver (http://creativecommons.org/publicdomain/zero/1.0/) applies to the data made available in this article, unless otherwise stated in a credit line to the data. 
(20.8\%), Switzerland (32.5\%), Spain (30-45\%), and England (46.5\%) [16-19]. Policymakers and public health professionals in rapidly aging Asian societies have therefore focused intently on ways to promote active lifestyles and increase LTPA participation in this population segment.

Men tend to exhibit higher prevalence of LTPA participation compared to women $[12,15,18]$. Aside from gender, other correlates that have been found to be positively associated with LTPA include age, education, family encouragement, social support from friends, and awareness of the benefits of exercise [12, 13]. In addition, psychosocial indicators such as self-perceptions of positive social relationships, intrinsic motivation, and perceived social ties were correlated to higher LTPA involvement $[20,21]$. Factors typically negatively associated with LTPA include number of chronic conditions, obesity, lack of time or company, having a job, worse self-rated health, and depression [12, 13, 18]. Fewer studies have examined correlates of LTPA participation in multi-ethnic populations. One exception is Tam et al. [22] which used a sample of 770 adults in Malaysia and found that physical activity levels were significantly related to ethnicity, gender, age, occupation, and educational level.

The current analysis explores the prevalence and correlates of regular LTPA participation in a large population-based sample of adults over age 50 in Singapore. Using 2018-2019 panel data, this present study seeks to (i) identify regular LTPA participation in January 2019, (ii) assess whether this health behavior was sustained over a period of time (specifically, 7 months), and (iii) examine the sociodemographic and health correlates of regular LTPA (measured both crosssectionally and over 7 months). A city-state in Southeast Asia, Singapore will become a super-aged country by around 2024 where one in five persons will be age $65+$ [23], and its residents are among the longest lived in the world. A Lancet study projects that average life expectancy at birth will increase from 83.3 years in 2016 to 85.4 years by 2040 in Singapore, placing it third highest out of the 195 countries evaluated [24]. Our study also fills an important gap in the literature by examining LTPA participation in a multi-ethnic population, and the panel design allows us to additionally explore whether factors predicting current participation are identical to those driving sustained participation.

\section{Methods}

Data

Data were from the Singapore Life Panel $\left(\mathrm{SLP}^{\circ}\right)$, an ongoing high-frequency (monthly) internet survey administered for a representative cohort of Singaporean citizens and permanent residents aged between 50 and 75 when first recruited at baseline in July 2015. Since then, the SLP has followed more than 12,000 Singaporeans over 5 years, and monthly response rates have remained high at around $70 \%$ over time [25]. Comparisons between SLP and official statistics showed close matching on age, sex, marital status, ethnicity, education, labor force status, income and expenditure [25]. While the SLP is administered online for a majority of respondents, those who are unable to understand the survey questions or lacking internet access can answer the survey over the phone or at centres located conveniently around Singapore. Consequently, attrition rate is low. Ethical approval for the study was obtained by the Centre for Research on the Economics of Ageing in the Singapore Management University, and informed consent was obtained from each participant. A complete description of the SLP is given elsewhere [25].

To a large extent, the SLP was modeled after the American Life Panel and featured questions and survey techniques adopted from more established surveys like the US Health and Retirement Study [25]. The core SLP survey includes questions on spending, health, employment, socioeconomic status, retirement expectations, and social networks. Additional survey questions, including those on leisure-time and social activities, are fielded for a limited period in special modules. Specifically, we used data on leisure-time activities from the July 2018, October 2018, and January 2019 waves. Subjects with missing information on leisure-time activities were excluded. The final analytical sample used in this study comprised 7684 community-dwelling persons over age 50. It consisted of $47.3 \%$ males and $52.7 \%$ females. The average age among sampled respondents was $62.5(\mathrm{SD}=$ 6.0). Singapore is a multiracial and multicultural country, with ethnic Chinese making up the majority of the population. This was reflected in the sample: $87.2 \%$ were Chinese Singaporeans, $5.8 \%$ were Malays, $5.1 \%$ were Indians, and $1.8 \%$ were others (e.g. Eurasians). The survey questionnaire was available in all four official languages of Singapore - English, Mandarin, Malay and Tamil.

\section{Measurement of regular LTPA}

Regular LTPA is defined as engaging in moderate and/ or vigorous physical activity during leisure time for at least several times a week, which includes three or more times per week for vigorous activity or at least five times a week for light-moderate activities [2-4]. SLP respondents were asked to indicate their monthly frequency of participation in social/leisure physical activities such as exercises, swimming, and brisk walking. These are moderate- or vigorous-intensity activities that typically last at least $20 \mathrm{~min}$ each time. The survey did not feature questions about individual activity types. Response categories for overall LTPA engagement were "daily", "several times 
per week", "once a week", "1-3 times a month", or "less than once a month". Using the January 2019 responses, we constructed a regular LTPA binary variable by combining the "daily" and "several times per week" responses into a "yes" category, and the other three responses into a "no" category. This was the main outcome variable of interest.

Data on LTPA were separately collated in July and October 2018 surveys from the same respondents. Thus in total, the sampled respondents' LTPA participation was observed at three points in time over a seven-month period (July 2018, inclusive - January 2019). To explore whether factors predicting current participation are identical to those driving sustained participation in LTPA, we constructed an additional outcome variable (for sustained LTPA) coded 1 if the respondents reported regular LTPA participation at all three assessment points, and 0 otherwise.

\section{Measurement of covariates}

Several correlates relating to LTPA were identified from previous studies $[12-14,18,20,21]$. These were measured and defined as follows: demographic characteristics including age $(50-54,55-59,60-64,65-69$, or $\geq 70$ ), gender (male or female), ethnicity/race (Chinese, Malay, Indian or others), and current marital status (married or no); socioeconomic information such as schooling/highest educational qualification (less than secondary, secondary, and tertiary), employment (fully retired or no), living arrangement (live alone or with others), income (in logs), and number of children (units); as well as health and lifestyle factors such have activity of daily living (ADL) disability (yes or no), have chronic condition (yes or no), ever smoked (yes or no), worse self-rated health (yes or no), and whether satisfied with one's social contacts and family life (yes or no).

The ADL disability measure referenced six items including difficulty dressing, walking across a room, bathing, eating, getting in or out of bed, and toileting (yes/no responses). The chronic condition measure was derived from the question: did a doctor tell you that you have any of the following conditions? (including hypertension, diabetes, cancer, heart problems, stroke, arthritis, and psychiatric problems; yes/ no responses). An affirmative response to any one item was considered as having ADL disability and having chronic condition, respectively. Respondents reported their health status as excellent, very good, good, fair, and poor. The responses were dichotomized into fair/poor (worse self-rated health) or excellent/very good/good [18]. Survey participants were asked to indicate their current employment situation (working for pay, retired, self-employed, student, and others). These were non-mutually exclusive options.
Those who stated retired and not working for pay or self-employed were considered fully retired.

Although less explored in previous studies, another potential confounder may be projected life expectancy. People who expect to live longer may be intrinsically more incentivized to participate in regular exercise. This factor is especially pertinent to Singapore's context given the longevity of its residents as discussed earlier. Accordingly, we included a proxy measure ("expect to live past age 75") was constructed from data on age and subjective life expectancy. For persons $\geq$ age 75 , this indicator variable was set to 1 ( $<1.5 \%$ of the sample). For persons < age 75, the indicator variable was coded 1 if the respondent stated $50 \%$ or more in reply to the question "What is the percent chance that you will live to be 75 or more?", 0 otherwise.

\section{Statistical analyses}

We analyzed men and women separately $[12,18]$. Standard statistical $\chi^{2}$ tests $(\alpha=0.05)$ for categorical data were conducted to determine if men and women significantly differ in their LTPA participation. Given a confirmatory result, we proceeded to analyze the prevalence and correlates of regular LTPA participation separately for men and women. First, we calculated descriptive measures for all variables of interest by gender. Second, we compared the reported prevalence for regular LTPA participation (January 2019 only) versus sustained participation over 7 months (July 2018 to January 2019). Third, we fitted logistic regression models by gender to assess factors independently associated for each dependent variable. Adjusted odds ratios (ORs) with their confidence intervals from multiple logistic regression models were reported. Statistical significance was established at $P<.01$ (two-tailed $P$ values). All statistical analyses were carried out using STATA version 16.0 (StataCorp, College Station, TX, USA).

\section{Results}

Table 1 shows the distribution of LTPA participation, sociodemographic characteristics, and health-related variables among our respondents. Of the 7684 respondents, $47.3 \%$ were men, $15.6 \%$ were aged 70 or older, $35.3 \%$ had tertiary education (more than 10 years of school), $79.2 \%$ were married, $21.7 \%$ were fully retired, and about a quarter $(25.2 \%)$ lived alone. On average, annual income was $\$ 51,700$ in Singapore dollars (approximately USD $\$ 36,000$ ) and respondents had about two living children. Slightly more than a third (39.9\%) of the sampled respondents rated their health as fair or poor, and $12.1 \%$ had ever smoked. Although $65.4 \%$ of the respondents reported having one or more chronic condition, only a small proportion (6.3\%) had 1+ ADL limitation. More than half $(58.3 \%)$ were currently satisfied with their 
Table 1 Descriptive Statistics and Distribution of Leisure-Time Physical Activity: Singapore Life Panel, 2019

\begin{tabular}{|c|c|c|c|}
\hline & $\begin{array}{l}\text { Total, } n(\%) \\
(n=7684)\end{array}$ & $\begin{array}{l}\text { Male, } n(\%) \\
(n=3632)\end{array}$ & $\begin{array}{l}\text { Female, } n(\%) \\
(n=4052)\end{array}$ \\
\hline \multicolumn{4}{|c|}{ Frequency of leisure-time physical activity/month } \\
\hline Less than once & $1595(20.8)$ & $671(18.5)$ & $924(22.8)^{* *}$ \\
\hline $1-3$ times & $1463(19.0)$ & $669(18.4)$ & $794(19.6)$ \\
\hline Once a week & $1571(20.4)$ & $745(20.5)$ & $826(20.4)$ \\
\hline Several times per week & $1761(22.9)$ & $878(24.2)$ & $883(21.8)^{*}$ \\
\hline Daily & $1294(16.8)$ & $669(18.4)$ & $625(15.4)^{* *}$ \\
\hline \multicolumn{4}{|l|}{ Age group } \\
\hline $50-54$ & $411(5.3)$ & $78(2.1)$ & $333(8.2)$ \\
\hline $55-59$ & $2379(31.0)$ & $1113(30.6)$ & $1266(31.2)$ \\
\hline $60-64$ & $2134(27.8)$ & $1030(28.4)$ & $1104(27.2)$ \\
\hline $65-69$ & $1560(20.3)$ & $783(21.6)$ & $777(19.2)$ \\
\hline$\geq 70$ & $1200(15.6)$ & $628(17.3)$ & $572(14.1)$ \\
\hline \multicolumn{4}{|l|}{ Race/ethnicity } \\
\hline Chinese & 6701 (87.2) & 3167 (87.2) & $3534(87.2)$ \\
\hline Malay & $447(5.8)$ & $204(5.6)$ & $243(6.0)$ \\
\hline Indian & $395(5.1)$ & $183(5.0)$ & $212(5.2)$ \\
\hline Others & $141(1.8)$ & $78(2.1)$ & $63(1.6)$ \\
\hline \multicolumn{4}{|l|}{ Schooling } \\
\hline Less than secondary & $1781(23.2)$ & $678(18.7)$ & $1103(27.2)$ \\
\hline Secondary & $3192(41.5)$ & $1390(38.3)$ & $1802(44.5)$ \\
\hline Tertiary & $2711(35.3)$ & $1564(43.1)$ & $1147(28.3)$ \\
\hline Married & $6084(79.2)$ & $3234(89.0)$ & $2850(70.3)$ \\
\hline Fully retired & $1669(21.7)$ & $924(25.4)$ & $745(18.4)$ \\
\hline Lives alone & $1935(25.2)$ & $863(23.8)$ & $1072(26.5)$ \\
\hline Income (in S\$’000) (SD) & $51.7(91.2)$ & $58.5(90.0)$ & $45.6(91.9)$ \\
\hline Number of children (SD) & $1.85(0.99)$ & $1.89(0.96)$ & $1.81(1.02)$ \\
\hline Worse self-rated health & 3065 (39.9) & $1443(39.7)$ & $1622(40.0)$ \\
\hline 1+ ADL limitation & $482(6.3)$ & $208(5.7)$ & $274(6.8)$ \\
\hline Have chronic condition(s) & $5022(65.4)$ & $2464(67.8)$ & $2558(63.1)$ \\
\hline Ever smoke & $928(12.1)$ & $798(22.0)$ & $130(3.2)$ \\
\hline Satisfied with social life & 4477 (58.3) & $2093(57.6)$ & $2384(58.8)$ \\
\hline Expect to live past age 75 & $1723(22.4)$ & 789 (21.7) & 934 (23.1) \\
\hline
\end{tabular}

${ }^{*} P<.05 ;{ }^{*} P<.01$ males vs. females. $S \$$ refers to Singapore dollars (approximate $1 \mathrm{~S} \$=\mathrm{USD} \$ 0.7$ )

social contacts and family life, and $22.4 \%$ expected to live/lived past age 75 .

About two-fifths (39.8\%) of the respondents participated in regular LTPA, with significantly higher proportions of men than women doing so. Univariate analysis by individual response categories showed that significantly higher percentages of men than women exercised daily $(P<.01)$ and several times a week $(P<.05)$. Furthermore, on the flip side, significantly lower percentages of men than women exercised less than once a month $(P<.05)$. Overall, this suggests that men and women in our sample differed in terms of their patterns of LTPA participation. Thus, the correlates of LTPA participation are analyzed separately for men and women. The distributions of sociodemographic and other covariates, except for smoking status, were generally quite similar among our male and female respondents.

Table 2 presents adjusted odds ratios for the likelihood of engaging in regular LTPA by gender. For men, variables significantly associated with LTPA participation were tertiary education, retired, income, satisfied with social life, worse self-rated health, age 70 and older, Malay, and 1+ ADL limitation. The magnitude of the estimated odds ratio for 'fully retired' was especially large as compared to the rest of the correlates, implying that transition into retirement is a key factor prompting LTPA participation among Singaporean men. Findings were similar for women, with the following exceptions: LTPA participation was also significantly associated with secondary education $(P<.01)$, but it was not significantly associated with $1+$ ADL limitation despite the estimated odds ratio being indicative of an inverse relationship with LTPA participation.

Table 3 presents a comparative set of results from logistic regressions using LTPA participation sustained over a period of 7 months as the dependent variable (1769 out of 7684 respondents did so). It reveals that the correlates of sustained LTPA participation were relatively consistent with factors predicting current participation at a point in time. The pseudo R-squareds indicated an improved model fit over those obtained in Table 2 for both sexes. For men, however, a key difference was that $1+$ ADL limitation was not significantly associated with LTPA sustained over time. Age was a strong and independent predictor of sustained regular exercise, controlling for other demographic and health factors. Women aged 65-69 and aged $\geq 70$ were 2.03 and 3.51 times, respectively, as likely to adhere to regular LTPA as compared to their counterparts in the 50-54 age group.

\section{Discussion}

Regular participation in recreational physical activities is important to promoting health and well-being among middle-aged and older adults as populations age. Yet, our study found that about three-fifths (60.2\%) of Singaporeans over age 50 in a large community-based sample do not participate in regular LTPA. While direct crossnational comparisons cannot be undertaken given different study populations and methodology, this rate seems to be comparable to other aging Asian societies such as China, but higher compared to Western societies. Also worrisome is the fact that Singapore is transitioning 
Table 2 Correlates of Regular Leisure-Time Physical Activity

\begin{tabular}{|c|c|c|c|c|c|c|}
\hline \multirow[b]{3}{*}{ Independent Variable } & \multicolumn{6}{|c|}{ Dependent Variable: LTPA in Jan 2019} \\
\hline & \multicolumn{3}{|c|}{ Men } & \multicolumn{3}{|c|}{ Women } \\
\hline & OR & & $\mathrm{Cl}$ & OR & & $\mathrm{Cl}$ \\
\hline \multicolumn{7}{|l|}{ Age group } \\
\hline $50-54$ (ref) & 1.00 & & & 1.00 & & \\
\hline $55-59$ & 1.71 & * & $(1.03,2.84)$ & 1.08 & & $(0.82,1.42)$ \\
\hline $60-64$ & 1.77 & * & $(1.07,2.95)$ & 1.28 & & $(0.97,1.70)$ \\
\hline $65-69$ & 2.05 & * & $(1.19,3.56)$ & 1.40 & & $(0.99,1.97)$ \\
\hline$\geq 70$ & 2.21 & $* *$ & $(1.24,3.94)$ & 2.20 & $* * *$ & $(1.50,3.23)$ \\
\hline \multicolumn{7}{|l|}{ Race/ethnicity } \\
\hline Chinese (ref) & 1.00 & & & 1.00 & & \\
\hline Malay & 0.56 & ** & $(0.40,0.78)$ & 0.52 & $* * *$ & $(0.37,0.72)$ \\
\hline Indian & 0.65 & * & $(0.46,0.90)$ & 0.76 & & $(0.55,1.03)$ \\
\hline Others & 1.29 & & $(0.80,2.08)$ & 1.18 & & $(0.70,2.00)$ \\
\hline \multicolumn{7}{|l|}{ Schooling } \\
\hline Less than secondary (ref) & 1.00 & & & 1.00 & & \\
\hline Secondary & 1.14 & & $(0.93,1.40)$ & 1.29 & ** & $(1.08,1.53)$ \\
\hline Tertiary & 1.92 & $* * *$ & $(1.56,2.38)$ & 1.85 & $* * *$ & $(1.52,2.26)$ \\
\hline Married & 0.94 & & $(0.74,1.21)$ & 0.99 & & $(0.84,1.16)$ \\
\hline Fully retired & 2.26 & $* * *$ & $(1.88,2.72)$ & 1.54 & $* * *$ & $(1.28,1.85)$ \\
\hline Lives alone & 0.99 & & $(0.83,1.18)$ & 1.19 & * & $(1.01,1.39)$ \\
\hline Income & 1.05 & $* * *$ & $(1.03,1.08)$ & 1.04 & $* * *$ & $(1.02,1.06)$ \\
\hline Number of children & 0.95 & & $(0.88,1.04)$ & 1.04 & & $(0.97,1.13)$ \\
\hline Worse self-rated health & 0.73 & $* * *$ & $(0.62,0.86)$ & 0.68 & $* * *$ & $(0.59,0.8)$ \\
\hline 1+ ADL limitation & 0.56 & $* *$ & $(0.40,0.79)$ & 0.93 & & $(0.70,1.22)$ \\
\hline Have chronic condition(s) & 0.90 & & $(0.77,1.05)$ & 0.93 & & $(0.80,1.07)$ \\
\hline Ever smoke & 0.91 & & $(0.76,1.08)$ & 1.87 & & $(0.58,1.27)$ \\
\hline Satisfied with social life & 1.44 & $* * *$ & $(1.23,1.69)$ & 1.75 & $* * *$ & $(1.51,2.03)$ \\
\hline Expect to live past age 75 & 1.10 & & $(0.91,1.33)$ & 1.12 & & $(0.94,1.32)$ \\
\hline \multicolumn{7}{|l|}{ Model fit: } \\
\hline Pseudo R2 & $8.0 \%$ & & & $6.1 \%$ & & \\
\hline
\end{tabular}

Note: $O R$ Odds ratio, $C I$ Confidence interval

${ }^{*} P<.05 ;{ }^{* *} P<.01 ; * * * P<.001$

quickly into a super-aged country where one in five of the residents will be aged 65 years and above. Although it was reported that $57.9 \%$ of elderly Singaporeans did not participate in regular LTPA in 1998 [8], the country was still relatively young then (share of population $\geq$ age $65=7.1 \%$; average life expectancy at birth $=77.3$ years ). By contrast, the resident population is now demographically matured (in 2019: share of population $\geq$ age $65=$ $16.0 \%$; average life expectancy at birth $=83.6$ years) [26] .

Factors positively associated with LTPA participation in both genders were age, education, retired, income, and satisfaction with social life, whereas a negative association was found with self-rated health. These findings are generally consistent with those of previous research
$[9,13]$, which showed higher age, higher education level, non-working, and better self-rated health, as important enabling factors. Our sensitivity analysis revealed that the correlates of sustained LTPA participation were relatively consistent with factors predicting current participation. While 1+ ADL limitation was predictive of a lower likelihood of engaging in exercise at a given timepoint, it is not a determinant of longer-term adherence to regular LTPA.

The positive association between the likelihood of LTPA participation and being retired was salient in Singapore's context because re-employment of older workers is encouraged up to age 67 (although statutory retirement age is 62 ). In 2019, the share of adults age 
Table 3 Correlates of Regular Leisure-Time Physical Activity Sustained Over 7 Months

\begin{tabular}{|c|c|c|c|c|c|c|}
\hline \multirow[b]{3}{*}{ Independent Variable } & \multicolumn{6}{|c|}{ Dependent Variable: LTPA (Jul 2018-Jan 2019) } \\
\hline & \multicolumn{3}{|l|}{ Men } & \multicolumn{3}{|c|}{ Women } \\
\hline & OR & & $\mathrm{Cl}$ & OR & & $\mathrm{Cl}$ \\
\hline \multicolumn{7}{|l|}{ Age group } \\
\hline $50-54$ (ref) & 1.00 & & & 1.00 & & \\
\hline $55-59$ & 1.26 & & $(0.69,2.32)$ & 1.04 & & $(0.75,1.46)$ \\
\hline $60-64$ & 1.48 & & $(0.81,2.72)$ & 1.26 & & $(0.90,1.77)$ \\
\hline $65-69$ & 2.39 & ** & $(1.26,4.57)$ & 2.03 & $* *$ & $(1.34,3.05)$ \\
\hline$\geq 70$ & 2.85 & ** & $(1.45,5.63)$ & 3.51 & $* * *$ & $(2.22,5.55)$ \\
\hline \multicolumn{7}{|l|}{ Race/ethnicity } \\
\hline Chinese (ref) & 1.00 & & & 1.00 & & \\
\hline Malay & 0.43 & $* * *$ & $(0.27,0.68)$ & 0.44 & $* * *$ & $(0.28,0.70)$ \\
\hline Indian & 0.65 & * & $(0.44,0.97)$ & 0.66 & * & $(0.44,0.98)$ \\
\hline Others & 1.59 & & $(0.98,2.57)$ & 0.57 & & $(0.29,1.12)$ \\
\hline \multicolumn{7}{|l|}{ Schooling } \\
\hline Less than secondary (ref) & 1.00 & & & 1.00 & & \\
\hline Secondary & 1.29 & & $(0.99,1.68)$ & 1.55 & $* * *$ & $(1.24,1.93)$ \\
\hline Tertiary & 2.29 & $* * *$ & $(1.76,2.97)$ & 2.18 & $* * *$ & $(1.71,2.79)$ \\
\hline Married & 0.84 & & $(0.64,1.11)$ & 0.99 & & $(0.82,1.20)$ \\
\hline Fully retired & 2.41 & $* * *$ & $(1.97,2.95)$ & 1.57 & $* * *$ & $(1.27,1.94)$ \\
\hline Lives alone & 0.93 & & $(0.76,1.14)$ & 1.19 & & $(0.99,1.43)$ \\
\hline Income & 1.07 & $* * *$ & $(1.04,1.10)$ & 1.04 & $* *$ & $(1.01,1.07)$ \\
\hline Number of children & 0.92 & & $(0.83,1.01)$ & 0.98 & & $(0.90,1.07)$ \\
\hline Worse self-rated health & 0.74 & $* *$ & $(0.61,0.89)$ & 0.66 & $* * *$ & $(0.54,0.79)$ \\
\hline 1+ ADL limitation & 0.73 & & $(0.48,1.11)$ & 1.01 & & $(0.72,1.43)$ \\
\hline Have chronic condition(s) & 1.04 & & $(0.87,1.24)$ & 0.89 & & $(0.75,1.06)$ \\
\hline Ever smoke & 0.86 & & $(0.70,1.06)$ & 0.82 & & $(0.49,1.38)$ \\
\hline Satisfied with social life & 1.72 & $* * *$ & $(1.42,2.07)$ & 1.84 & $* * *$ & $(1.53,2.21)$ \\
\hline Expect to live past age 75 & 1.18 & & $(0.95,1.47)$ & 1.07 & & $(0.87,1.32)$ \\
\hline \multicolumn{7}{|l|}{ Model fit: } \\
\hline Pseudo R2 & $10.5 \%$ & & & $8.0 \%$ & & \\
\hline
\end{tabular}

Note: $O R$ Odds ratio, $C l$ Confidence interval

${ }^{*} P<.05 ;{ }^{* *} P<.01 ;{ }^{* * *} P<.001$

55-64 participating in the labor force is about 70\%, with a higher labour force participation rate among men than women [27]. This rationalizes the comparatively large effect of 'fully retired' on LTPA participation in the regressions (particularly for men), as well as the positive association observed between LTPA participation and $\geq$ age 70. Thus, while aging societies seek to enhance the employability and retention of older workers in their (shrinking) workforce, the trade-off is that individuals who are still working are less likely to be physically active due to lack of time.

Our finding that satisfaction with social life was significantly associated with regular LTPA participation both cross-sectionally and over time $(P<.001$ in both cases $)$ is consistent with emerging evidence that positive perceived social relationships and social ties are correlated to LTPA participation in the US and elsewhere [20,21]. This has important implications in terms of public health interventions targeted at helping middle-aged and older adults develop positive attitudes on social interactions linked to their health behaviour.

Our results also indicated significant ethnic differences in regular LTPA participation, controlling for sociodemographic and health characteristics. Specifically, Singaporean Malays were less likely to engage in exercise than their Chinese peers $(P<.001)$. This finding concurs with prior research which have investigated patterns of physical activity in multi-ethnic Asian urban populations [22, 28, 29]. One 
study, in particular, showed that elderly Chinese in multiethnic Malaysia were more physically active than their Indian and Malay counterparts [28]. Descriptive statistics from the Singapore Health 2012 study had also reported lower prevalence of regular LTPA (assessed using the Global Physical Activity Questionnaires) among Malay participants compared to other major ethnic groups [29]. Although our study did not look specifically at respondents' reasons for not exercising, other studies have suggested that ethnic/ cultural norms related to physical activity (e.g., perceptions of whether it is a priority or desirable) may influence LTPA participation [22].

The strengths of this present study are its communitybased, prospective design, and the sample is approximately three times larger than those employed in previous Singapore-based studies [12, 29]. We also adjusted for potential confounders such as satisfaction with social life, in addition to more conventional covariates. This study, however, has its limitations. First, the physical activity measure was self-reported and might be subject to recall bias or imprecise measurement. In our case, the fairly consistent LTPA responses elicited from each individual at different time-points provided some reassurance. Second, the data did not distinguish across different types of leisure physical activity nor include information about the intensity or duration of the activity. Finally, we examined sustained regular LTPA over a relatively short period of 7 months. Future research on LTPA covering longer follow-up periods and with richer measures on the different activity types and ethnic/ cultural norms will be required to investigate further the determinants of persistent LTPA participation.

\section{Conclusions}

Lack of physical activity is a pressing public health issue worldwide, especially in rapidly aging Asian countries, where the lack of LTPA participation among middleaged and older adults is most prevalent. Our study indicates that only about two-fifths of adults over age 50 in a large, multi-ethnic population-based sample in Singapore regularly engaged in LTPA in 2019. Factors associated with LTPA participation in both genders were age, ethnicity, education, fully retired, income, self-rated health, and satisfaction with social life. Physical activity promotion incorporating psychosocial intervention may help individuals develop positive attitudes on social interactions and social ties, which in turn, encourage LTPA participation. On cultural norms, more work needs to be done to understand potential differences in ethnic attitudes towards physical activity and to find ways of making LTPA more desirable for those who have the time and resources to participate. Policymakers need to evaluate the appropriate mix of strategies required to increase recreational physical activity levels in this demographic segment, and carefully weigh the health consequences of further increases in the statutory retirement age. Finally, efforts should be made to strengthen the monitoring of leisure activity engagement across various segments of adults, ranging from the middle-aged to the young-old to the oldest-old, so that effective lifestyle interventions can be more suitably developed and targeted at different population subgroups.

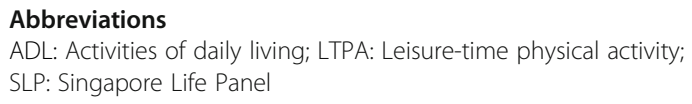

\section{Acknowledgements}

N/A

\section{Author's contributions}

JF designed the study and was responsible for the collection, analysis, and interpretation of data, as well as writing the manuscript. The author(s) read and approved the final manuscript.

\section{Funding}

The research was supported by the Singapore Ministry of Education Academic Research Fund Tier 3 grant (MOE2013-T3-1-009) at the Singapore Management University, and the MOE Start-up Grant (R603-000-267-133) at the National University of Singapore. The funding body did not influence this paper in any way prior to circulation.

\section{Availability of data and materials}

The data that support the findings of this study are available from the Singapore Management University but restrictions apply to the availability of these data, which were used under license for the current study, and so are not publicly available. Data are however available from the authors upon reasonable request and with permission of the Singapore Management University. More information about the Singapore Life Panel can be found at (https://rosa.smu.edu.sg/singapore-monthly-panel).

Ethics approval and consent to participate

Not applicable.

\section{Consent for publication}

Not applicable.

\section{Competing interests}

The authors declare that they have no competing interests.

Received: 10 August 2020 Accepted: 12 February 2021

Published online: 18 February 2021

\section{References}

1. Kandula NR, Lauderdale DS. Leisure time, non-leisure time, and occupational physical activity in Asian Americans. Ann Epidemiol. 2005;15(4):257-65.

2. Ainsworth BE, Haskell WL, Leon AS, et al. Compendium of physical activities: classification of energy costs of human physical activities. Med Sci Sports \& Exerc. 1993;25(1):71-80.

3. Garber CE, Blissmer B, Deschenes MR, et al. American College of Sports Medicine position stand. Quantity and quality of exercise for developing and maintaining cardiorespiratory, musculoskeletal, and neuromotor fitness in apparently healthy adults: guidance for prescribing exercise. Med Sci Sports Exerc. 2011:43(7):1334.

4. National Health Interview Survey: Comparison of Two Recodes - Core and Supplement Leisure-time Physical Activity Questions. National Center for Health Statistics, Centers for Disease Control and Prevention. 2015. Available at: https://www.cdc.gov/nchs/nhis/physical_activity/pa_comparison.htm. Accessed 15 Jan 2021

5. Singh MAF. Exercise comes of age: rationale and recommendations for a geriatric exercise prescription. J Gerontol A Biol Sci Med Sci. 2002;57(5): M262-82. 
6. Boyle PA, Buchman AS, Wilson RS, Bienias $J$, Bennett DA. Physical activity is associated with incident disability in community-based older persons. J Am Geriatr Soc. 2007;55(2):195-201.

7. Nelson ME, Rejeski WJ, Blair SN, et al. Physical activity and public health in older adults: recommendation from the American College of Sports Medicine and the American Heart Association. Med Sci Sports Exerc. 2007;39(8):1435-45.

8. Chodzko-Zajko WJ, Proctor DN, Singh MAF, et al. Exercise and physical activity for older adults. Med Sci Sports Exerc. 2009;41(7):1510-30.

9. King AC, Guralnik JM. Maximizing the potential of an aging population. JAMA. 2010;304(17):1944-5.

10. Start active, stay active. A report on physical activity from the four home countries' Chief Medical Officers. London: Department of Health; 2011.

11. Ku PW, Fox KR, Chen L. Leisure-time physical activity, sedentary behaviors and subjective well-being in older adults: an eight-year longitudinal research. Soc Indic Res. 2016;127(3):1349-61.

12. Lian WM, Gan GL, Pin CH, Wee S, Ye HC. Correlates of leisure-time physical activity in an elderly population in Singapore. Am J Public Health. 1999;89(10):1578-80.

13. Pan LY, Hsu HC, Chang WC, Luh DL. Trajectories of physical activity and risk factors among Taiwanese older adults. Int J Behav Med. 2015;22(1):62-9.

14. Feng $\mathrm{Q}$, Purser $\mathrm{J}$, Zhen Z, Duncan PW. Less exercise and more TV: leisure-time physical activity trends of Shanghai elders, 1998-2008. J Public Health. 2011:33(4):543-50.

15. Feng $\mathrm{Q}$, Fong JH, Zhang W, Liu C, Chen H. Leisure activity engagement among the oldest-old in China, 1998 to 2018. Am J Public Health. 2020; 110(10):1535-7.

16. Birdsey J, Sussell AL. Prevalence of obesity, no leisure-time physical activity, and short sleep duration among occupational groups in 29 states. J Occup Environ Med. 2017;59(12):1221-8.

17. Meyer K, Rezny L, Breuer C, Lamprecht M, Stamm HP. Physical activity of adults aged 50 years and older in Switzerland. Soc Prev Med. 2005;50(4):218-29.

18. Palacios-Ceña D, Alonso-Blanco C, Jiménez-Garcia R, et al. Time trends in leisure time physical activity and physical fitness in elderly people: 20 year follow-up of the Spanish population national health survey (1987-2006). BMC Public Health. 2011;11(1):799.

19. Active People Survey 2014/2015. Sport England. Available at: https://a ctivepeople.sportengland.org. Accessed 22 Jun 2020.

20. Clark PG, Riebe D, Blissmer BJ, Lees FD, Greaney ML. Psychosocial factors associated with physical activity in older adults. Annu Rev Gerontol Geriatr. 2016;36(1):273-91.

21. Lee $\mathrm{S}$, Lee $\mathrm{C}$, An J. Psycho-social correlates of leisure-time physical activity (LTPA) among older adults: a multivariate analysis. Eur Rev Aging Phys Act. 2020;17(1):1-7.

22. Tam CL, Bonn G, Yeoh SH, Yap CC, Wong CP. Physical activity and its correlates among adults in Malaysia: a cross-sectional descriptive study. PLoS One. 2016;11(6):e0157730.

23. Singapore: a super-aged country? Singapore: National Population and Talent Division, Strategy Group, Prime Minister's Office; 2016.

24. Foreman K, Marquez N, Dolgert A, et al. Forecasting life expectancy, years of life lost, and all-cause and cause-specific mortality for 250 causes of death: reference and alternative scenarios for 2016-40 for 195 countries and territories. Lancet. 2018:392(10159):2052-90.

25. Vaithianathan R, Hool B, Hurd MD, Rohwedder S. High-frequency internet survey of a probability sample of older Singaporeans: the Singapore life panel$^{\bullet}$. Singapore Econ Rev. 2018;1842004.

26. Life expectancy by sex, annual. Singapore Department of Statistics. Available at: https://www.singstat.gov.sg/. Accessed 22 Jun 2020

27. Table LFS. Ministry of Manpower. Singapore. Available at: https://stats.mom. gov.sg/Pages/Labour-Force-Summary-Table.aspx. Accessed Jun 22, 2020

28. Shaw BA, Spokane LS. Examining the association between education level and physical activity changes during early old age. J Aging Health. 2008;20: 767-87.

29. Win AM, Yen LW, Tan KH, Lim RB, Chia KS, Mueller-Riemenschneider F. Patterns of physical activity and sedentary behavior in a representative sample of a multi-ethnic south-east Asian population: a cross-sectional study. BMC Public Health. 2015;15(1):318.

\section{Publisher's Note}

Springer Nature remains neutral with regard to jurisdictional claims in published maps and institutional affiliations.

Ready to submit your research? Choose BMC and benefit from:

- fast, convenient online submission

- thorough peer review by experienced researchers in your field

- rapid publication on acceptance

- support for research data, including large and complex data types

- gold Open Access which fosters wider collaboration and increased citations

- maximum visibility for your research: over $100 \mathrm{M}$ website views per year

At BMC, research is always in progress.

Learn more biomedcentral.com/submissions 